\title{
AVALIAÇÃO DE GENÓTIPOS DE Leucaena spp. NAS CONDIÇÕES EDAFOCLIMÁTICAS DE SÃO CARLOS,SP: II. DETERMINAÇÕES BROMATOLÓGICAS NO PERÍODO DE ESTABELECIMENTO
}

\author{
A.C.P. de A. PRIMAVESI; A.R.A. NOGUEIRA; O. PRIMAVESI; R. GODOY; L.A.R. BATISTA; \\ N.J. NOVAES \\ Centro de Pesquisa de Pecudria do Sudeste/EMBRAPA, C.P. 339, CEP: 13560-970 - Säo Cartos,SP. \\ M.S. FRANÇA-DANTAS \\ Centro de Pesquisa Agropecuaria dos Cerrados/EMBRAPA, C.P. 08-223, CEP: 73301-970 - Brasalia,DF.
}

RISUMO: Em experimento condurido em Latossolo Vermelho-Amarelo distrofico, em área da EMBRAPA - CPPSE em Săo Carlos, situada a 2201'S e 4753'W, com altitude de $856 \mathrm{~m}$ e média de precipitação anual de $1502 \mathrm{~mm}$, procedeu-se a determinação da composiçăo bromatologica de folhas, hastes com diametro menor que 6 mm e vagens, de genotipos de leucena. Os genotipos avaliados, foram: L.leucocephala cv. Texas 1074 (T1), L.Leucocephala 29 A9 (T2), L.leucocephala 11 x L.diversifolla 25 (T3), L.leucocephala 11 x L.diversifolia 26 (T4), L.Leucocephala 24-19/2-39 x L.diversifolia 26 (T5) e L.leucocephala cr. Cunningham (testemunha). Verificou-se que: os genótipos avaliados năo apresentaram diferenças nas determinaçoes bromatologicas, realizadas nas folhas e talos finos; 0 genotipo T3 registrou o maior teor de proteina bruta $(28,06 \%)$, de fósforo $(0,29 \%)$ e a maior relaçäo PB/FDN e o menor teor de FDN para vagens; os genotipos apresentaram os seguintes teores médios, em porcentagem, para a composição bromatologica das folhas, vagens e talos finos, respectivamente: Proteína bruta $(18,57 ; 21,68 ; 6,41)$; Fibra detergente neatro $(29,09 ; 41,58 ; 71,01)$; Fósforo $(0,12 ; 0,22 ; 0,06)$; Cácio $(1,39 ; 0,36 ; 0,49)$; Magnésio $(0,51 ; 0,28 ; 0,24)$; Tanino $(1,32 ; 1,15 ; 0,28)$ e Digestibilidade "in vitro" $(58,39 ; 61,22 ; 33,61)$; os teores de proteina e fosforo apresentaram a seguinte ordem decrescente nas partes das plantas: vagens $>$ folhas $>$ talos finos; os teores de calcio: follas $>$ talos finos > vagens e de magnesio: folhas > vagens > talos finos.

Deseritarea: Leucaena spp., avaliação de genotipos, determinaçóes bromatologicas.

\section{EVALUATION OF Leuceena spp. GENOTYPES IN THE EDAPHIC AND CLIMATIC CONDITIONS OP SÃo CARLOS,SP: II. BROMATOLOGICAL DETERMINATIONS AT THE ESTABLISHMENT PERIOD}

\begin{abstract}
In a trial conducted on a distrofic Red-Yellow Latossol, at EMBRAPA-CPPSE, São Carlos, located at 2201 'S and $47^{\circ} 53$ 'W, altitude of $856 \mathrm{~m}$ and with a mean annual rainfall of $1502 \mathrm{~mm}$, the bromatological composition of leaves, stems smaller than $6 \mathrm{~mm}$ diameter and pods of leucena genotypes was determined. The genotypes evaluated were: L.leucocephala cv. Texas 1074 (T1), L.leucocephala 29 A9 (T2), L.leucocephala $11 \times$ L.diversifolia 25 (T3), L.leucocephala 11 x L.diversifolia 26 (T4), L.leucocephala 24-19/2-39 x L.diversifolia 26 (T5) and $L$.leucocephala cv. Cunningham (control). It was found that: - The evaluated genotypes did not show differences among themselves for bromatological determinations on leaves and fine stems; - T3 genotype had the greatest content of crude protein $(28.06 \%$ ), phosphorus $(0.29 \%)$, the greatest PB/FDN relation, and the smaller FDN content of pods; - The genotypes presented the following average percentual contents of the bromatological composition of leaves, pods and stems smaller than $6 \mathrm{~mm}$ diameter, respectively: Crude Protein $(18.57 ; 21.68 ; 6.41)$; Neutral detergent fiber (29.09; 41.58; 71.01); Phosphorus (0.12; 0.22; 0.06); Calcium (1.39; 0.36; 0.49); Magnesium (0.51; 0.28; 0.24); Tannin (1.32; 1.15; 0.28) and "in vitro" digestibility (58.39; 61.22; 33.61); - Protein and phosphorus contents presented the following decreasing order in plant parts: pods $>$ leaves $>$ stems smaller than 6 mm diameter; calcium contents: leaves $>$ stems smaller than $6 \mathrm{~mm}$ diameter $>$ pods; and the magnesium: leaves $>$ pods $>$ stems smaller than $6 \mathrm{~mm}$ diameter.
\end{abstract}

Keg Wonis: Leucaena sp., evaluation of genotypes, bromatological determinations. 


\section{INTRODUÇÃo}

A leucena é uma leguminosa muito apreciada pelos bovinos. As suas folhas, hastes com diâmetro menor que $6 \mathrm{~mm}$, flores e vagens se constituem numa excelente fonte de minerais e proteínas (GARCIA, 1986).

Segundo JONES (apud GARCIA, 1986), a composição protéica e de minerais da leucena pode ser comparada à da alfafa. Este mesmo autor relata que o tanino presente na leucena pode evitar a degradação da proteína no rúmen, tomando-a mais assimilável no intestino delgado e que se tem pouca informação sobre sua digestibilidade.

O conhecimento da composição mineral de uma planta é importante para estudos de nutrição animal. $O$ presente trabalho, utilizando diversos genótipos de leucena, pretendeu determinar os teores de proteína, cálcio, magnésio, fósforo, tanino e fibra detergente neutro, presentes nesses materiais e a sua digestibilidade "in vitro" na matéria seca, procurando verificar quais os genótipos que apresentam a melhor composição bromatológica.

\section{MATERIAIS E MÉTODOS}

O experimento foi conduzido em Latossolo Vermelho-Amarelo distrófico, na EMBRAPA-CPPSE de São Carlos, situada a $22^{\circ} 01^{\prime} \mathrm{S}$ e $47^{\circ} 53^{\prime} \mathrm{W}$, com altitude de $856 \mathrm{~m}$ e média de precipitação anual de $1502 \mathrm{~mm}$.

As características químicas do solo onde foi instalado o experimento encontram-se na TABELA 1.

Antes da instalação, a área foi adubada com $450 \mathrm{~kg} / \mathrm{ha}$ de superfosfato simples, $100 \mathrm{~kg}$ de $\mathrm{KCl}$ e $25 \mathrm{~kg} / \mathrm{ha}$ de FTE Br-12. Não foi aplicado calcário, pois pretendia-se uma saturação por bases de $25 \%$.

Os genótipos utilizados, foram: $\boldsymbol{L}$. eucocephala cv. Texas 1074 (T1); L. leucocephala 29 A9 (T2); L. leucocephala $11 \times$ L.diversifolia 25 (T3); L.leucocephala $11 \times$ L.diversifolia 26 (T4); L. leucocephala 24-19/2-39 $\times$ L.diversifolia 26(T5); L. leucocephala cv. Cunningham (C) (testemunha).

$O$ delineamento experimental foi o de blocos ao acaso com três repetições. As parcelas apresentavam 4 linhas de $7 \mathrm{~m}$ de comprimento, espaçadas de $2 \mathrm{~m}$ entre as linhas. Os 5 metros medianos das duas linhas centrais, representavam a área útil.

A semeadura foi realizada em 08/02/89, com 20 sementes viáveis por metro linear, a uma profundidade de $3 \mathrm{~cm}$. As sementes foram previamente escarificadas com água a $80^{\circ} \mathrm{C}(2 \mathrm{~min}$.) e inoculada com inoculante específico. A emergência ocorreu 12 dias após o plantio. Aos 100 dias após a instalação, foi feito desbaste, deixando-se aproximadamente 5 plantas por metro linear.

Após 15 meses foi efetuado corte a 30-40 $\mathrm{cm}$ do solo, para avaliação dos genótipos no estabelecimento. As plantas foram então separadas em folhas, vagens e hastes com diâmetro menor que $6 \mathrm{~mm}$. Após a pesagem, foram separados 500 $g$ de matéria fresca, que permaneceram na estufa a $60^{\circ} \mathrm{C}$, até peso constante, sendo esta moída em moinho tipo Wiley com peneira de malha de 20 Mesh (SARRUGE \& HAAG, 1974).

Determinou-se o nitrogênio pelo método microkjeldahl (ASSOCIATION OF OFFICIAL AGRICULTURAL CHEMISTS, 1970), obtendo-se a proteína multiplicando-se pelo fator 6,25 . Através de digestão nitroperclórica, obteve-se o extrato onde foram determinados Cálcio e Magnésio por titulação com EDTA; Fósforo, por colorimetria e Potássio por fotometria de chama. A digestibilidade "in vitro" foi determinada pelo método de Tilley $\&$ Terry (SILVA, 1981), Fibra detergente neutro (SOEST, 1963) e Tanino, segundo FOLIN-DENIS (BURNS, 1983).

\section{RESULTADOS}

Os resultados das determinações de proteína bruta, FDN, digestibilidade "in vitro", P, Ca e Mg das partes consumíveis se encontram nas TABELAS 2, 3 e 4, respectivamente nas folhas, vagens e talos finos, para os genótipos avaliados.

Não houve diferença entre os genótipos avaliados, para determinações bromatológicas das folhas e talos finos.

Para vagens, o genótipo T3 apresentou o maior teor de proteína $(28,06)$, de fósforo $(0,29 \%)$ e a maior relação $\mathrm{PB} / F D N$ e o menor teor de FDN.

Os teores de proteína bruta nas folhas variaram de $17 \%$ a $20 \%$, nas vagens de $18 \%$ a $28 \%$ e nos talos finos de 5 a $8 \%$. Valores obtidos por SEIFFERT \& THIAGO (1983), foram semelhantes para folhas e vagens e pouco maiores para hastes finas ( 8 a $10 \%$ de proteína bruta).

Os teores de cálcio variaram de 0,41 a $0,58 \%$ para talos finos, de 0,15 a $0,51 \%$ para vagens e de 1,18 a $1,57 \%$ para folhas. 
TABELA 1 - Características químicas do solo.

\begin{tabular}{|c|c|c|c|c|c|c|c|c|c|}
\hline \multirow{2}{*}{$\begin{array}{l}\text { Prof. } \\
\text { (cm) }\end{array}$} & \multirow{2}{*}{$\begin{array}{c}\mathrm{pH} \\
\mathrm{CaCl}_{2} \\
\end{array}$} & \multirow{2}{*}{$\begin{array}{l}\text { P resina } \\
\mathrm{ug} / \mathrm{cm}^{3}\end{array}$} & \multirow{2}{*}{$\begin{array}{l}\text { M.O. } \\
(\%)\end{array}$} & $\mathbf{K}$ & $\mathrm{Ca}$ & $\mathbf{M g}$ & $\mathrm{H}+\mathrm{Al}$ & CTC & \multirow{2}{*}{$\begin{array}{l}\mathrm{V} \\
(\%)\end{array}$} \\
\hline & & & & \multicolumn{5}{|c|}{$\mathrm{meq} / 100 \mathrm{~cm}^{3}$ solo } & \\
\hline $0-30$ & 4,8 & 3 & 2,0 & 0,13 & 0,8 & 0,07 & 3,6 & 4,6 & 22 \\
\hline $30-60$ & 4,4 & 1 & 1,9 & 0,10 & 0,6 & 0,04 & 3,8 & 4,5 & 16 \\
\hline
\end{tabular}

TABELA 2 - Teores de proteína bruta, FDN, $\mathrm{P}, \mathrm{Ca}, \mathrm{Mg}$, digestibilidade "in vitro", tanino e relação PB/FDN, das folhas de leucena (médias de 3 repetiçōes).

\begin{tabular}{ccccccccc}
\hline $\begin{array}{c}\text { Trata- } \\
\text { mentos }\end{array}$ & $\begin{array}{c}\text { PB } \\
(\%)\end{array}$ & $\begin{array}{c}\text { FDN } \\
(\%)\end{array}$ & $\begin{array}{c}\text { P } \\
(\%)\end{array}$ & $\begin{array}{c}\text { Ca } \\
(\%)\end{array}$ & $\begin{array}{c}\text { Mg } \\
(\%)\end{array}$ & $\begin{array}{c}\text { DV } \\
(\%)\end{array}$ & PB/FDN & $\begin{array}{c}\text { Tanino } \\
(\%)\end{array}$ \\
\hline T1 & 18,75 & 28,75 & 0,12 & 1,40 & 0,52 & 59,67 & $0,66 \mathrm{ab}^{*}$ & 1,26 \\
T2 & 17,10 & 29,19 & 0,10 & 1,18 & 0,44 & 56,33 & $0,58 \mathrm{~b}$ & 1,37 \\
T3 & 18,99 & 29,81 & 0,12 & 1,24 & 0,51 & 58,67 & 0,64 ab & 1,47 \\
T4 & 17,86 & 29,06 & 0,11 & 1,57 & 0,47 & 53,67 & 0,62 ab & 1,38 \\
T5 & 18,54 & 31,50 & 0,12 & 1,49 & 0,55 & 62,00 & 0,59 b & 1,15 \\
C & 20,18 & 26,24 & 0,13 & 1,47 & 0,58 & 60,00 & 0,78 a & 1,27 \\
X & 18,57 & 29,09 & 0,12 & 1,39 & 0,51 & 58,39 & - & 1,32 \\
\hline \hline
\end{tabular}

* Valores seguidos da mesma letra na mesma coluna, não diferem estatisticamente (P > 0,05, Tukey) ** PB = Proteína bruta; FDN = Fibra detergente neutro; $\mathrm{P}=$ Fósforo; $\mathrm{Ca}=$ Cálcio; $\mathbf{M g}=$ Magnésio; DV = Digestibilidade "in vitro".

Os teores de fósforo oscilaram de 0,05 a $0,08 \%$ nos talos finos, de 0,16 a $0,29 \%$ nas vagens e de 0,12 a $0,13 \%$ nas folhas. A relação $\mathrm{Ca}: \mathrm{P}$ nas folhas foi de 11:1. Os teores de magnésio foram de 0,19 a $0,29 \%$ nos talos finos, de 0,22 a $0,40 \%$ nas vagens e de $0,44 \%$ a $0,58 \%$ nas folhas. Teores de tanino variaram de 1,15 a $1,47 \%$ nas folhas, de 0,81 a $1,47 \%$ nas vagens e de 0,23 a $0,35 \%$ nos talos finos. A digestibilidade "in vitro" variou de 54 a $62 \%$ nas folhas, de 51 a $67 \%$ nas vagens e de 31 a $38 \%$ nos talos finos.

Segundo Jones (apud GARCIA, 1986), a concentração de cálcio em leucena varia muito, dependendo do meio onde $\epsilon$ cultivada e dificilmente supera $1 \%$ na matéria seca. $O$ autor relata que o tanino pode exercer proteção contra a degradação de proteína no rúmen, tornando-a mais assimilável no intestino delgado e que se tem poucas informações sobre a digestibilidade de leucena. UPADHYAY et al. (1974), encontraram teores foliares de $2,7 \%$ de cálcio e $0,17 \%$ de fósforo (Ca:P= 16:1); e $71 \%$ de digestibilidade na matéria seca de leucena. KLUTHCOUSKI (1982) cita teores foliares de fósforo variando de 0,17 a 0,22\%; cálcio, de 0,69 a 0,86\% (Ca:P = 4:1); e de magnesio, de 0,50 a $0,56 \%$. HUTTON (1982) cita análise foliar de espécies de leucena com teores de Ca variando de 0,12 a 0,74\%; fósforo, de 0,10 a $0,125 \%$ e magnésio, de 0,16 a $0,35 \%$. Parbery (apud SKERMAN, 1977), relata digestibilidade de materia seca de leucena variando de 65 a $87 \%$. GARCIA (1986), citando a National Academy of Science (1977), relata teores foliares de tanino de 1,02 . 
TABELA 3 - Teores de proteína bruta, FDN, $\mathrm{P}, \mathrm{Ca}, \mathrm{Mg}$, digestibilidade "in vitro", tanino e relação PB/FDN das vagens de leucena (médias de 3 repetições).

\begin{tabular}{|c|c|c|c|c|c|c|c|c|}
\hline $\begin{array}{l}\text { Trata- } \\
\text { mentos }\end{array}$ & $\begin{array}{l}\mathrm{PB}^{-} \\
(\%)\end{array}$ & $\begin{array}{l}\text { FDN } \\
(\%)\end{array}$ & $\begin{array}{c}P \\
(\%)\end{array}$ & $\begin{array}{l}\mathrm{Ca} \\
(\%) \\
\end{array}$ & $\begin{array}{l}\mathrm{Mg} \\
(\%)\end{array}$ & $\begin{array}{l}\text { DV } \\
(\%)\end{array}$ & PB/FDN & $\begin{array}{c}\text { Tanino } \\
(\%)\end{array}$ \\
\hline $\mathbf{T} 1$ & $20,79 \mathrm{~b}^{*}$ & $23,06 \mathrm{a}$ & 0,22 bc & $0,31 \mathrm{ab}$ & $0,25 \mathrm{~b}$ & 64,00 & $0,50 \mathrm{~b}$ & $1,47 \mathrm{a}$ \\
\hline $\mathrm{T} 2$ & $18,52 \mathrm{~b}$ & $41,85 \mathrm{a}$ & $0,16 \mathrm{c}$ & $0,28 a b$ & $0,22 \mathrm{~b}$ & 51,00 & $0,44 \mathrm{~b}$ & $1,32 \mathrm{ab}$ \\
\hline T3 & $28,06 \mathrm{a}$ & $23,66 \mathrm{~b}$ & $0,29 \mathrm{a}$ & $0,15 \mathrm{~b}$ & $0,23 \mathrm{~b}$ & 61,00 & $1,19 \mathrm{a}$ & - \\
\hline T4 & $18,94 \mathrm{~b}$ & $45,35 \mathrm{a}$ & 0,18 bc & $0,42 \mathrm{a}$ & $0,24 \mathrm{~b}$ & 58,67 & $0,42 \mathrm{~b}$ & $1,33 \mathrm{ab}$ \\
\hline T5 & $21,20 \mathrm{~b}$ & $48,08 \mathrm{a}$ & $0,22 b c$ & $0,51 \mathrm{a}$ & $0,34 a b$ & 66,00 & $0,44 \mathrm{~b}$ & $0,83 \mathrm{~b}$ \\
\hline C & $22,59 \mathrm{~b}$ & $47,46 \mathrm{a}$ & $0,24 a b$ & 0,51 a & $0,40 a$ & 66,67 & $0,48 \mathrm{~b}$ & $0,81 \mathrm{~b}$ \\
\hline $\mathrm{X}$ & 21,68 & 41,58 & 0,22 & 0,36 & 0,28 & 61,22 & - & 1,15 \\
\hline
\end{tabular}

* Valores seguidos da mesma letra, dentro de cada coluna, não diferem estatisticamente ( $P>0,05$, Tukey)

TABELA 4 - Teores de proteína bruta, FDN, P, Ca, $\mathrm{Mg}$, digestibilidade "in vitro", tanino e relação PB/FDN, de talos finos de leucena (médias de 3 repetições).

\begin{tabular}{ccccccccc}
\hline \hline Trata- & PB & FDN & P & Ca & Mg & DV & PB/FDN & Tanino \\
mentos & $(\%)$ & $(\%)$ & $(\%)$ & $(\%)$ & $(\%)$ & $(\%)$ & & $(\%)$ \\
\hline T1 & $8,18^{*}$ & 67,03 & 0,08 & 0,58 & 0,27 & 38,00 & 0,12 & 0,35 \\
T2 & 5,31 & 72,53 & 0,05 & 0,54 & 0,26 & 33,33 & 0,07 & 0,28 \\
T3 & 5,30 & 73,16 & 0,05 & 0,41 & 0,24 & 32,33 & 0,07 & 0,25 \\
T4 & 6,30 & 72,78 & 0,05 & 0,47 & 0,22 & 31,33 & 0,09 & 0,23 \\
T5 & 6,35 & 70,76 & 0,06 & 0,42 & 0,19 & 32,33 & 0,09 & 0,30 \\
C & 7,05 & 69,85 & 0,07 & 0,55 & 0,29 & 34,33 & 0,10 & 0,25 \\
X & 6,41 & 71,01 & 0,06 & 0,49 & 0,24 & 33,61 & - & 0,28 \\
\hline \hline
\end{tabular}

* Valores seguidos da mesma letra, dentro de cada coluna, não diferem estatisticamente $(P>0,05$, Tukey).

\section{CONCLUSÕES}

1) Os genótipos avaliados não diferiram durante o período de estabelecimento, quanto aos teores de proteína, FDN, $\mathrm{P}, \mathrm{Ca}, \mathrm{Mg}$, tanino e digestibilidade "in vitro", tanto para folhas como para talos finos;
2) Os teores médios de proteína e fósforo, dos diversos genótipos estudados, apresentaram a seguinte ordem decrescente nas partes das plantas: vagem $>$ folhas $>$ talo fino. Os teores médios de cálcio: folhas > talo fino > vagem; e de magnésio: folhas $>$ vagem $>$ talo fino. Os teores

Sci. agric., Piracicaba, 51(1):53-57, jan./abr., 1994 
médios de tanino foram semelhantes para folhas $e$ vagens, mas maiores que os dos talos finos. Os teores médios de FDN foram maiores para talos finos, decrescendo para vagens e folhas;

3) Os diversos materiais apresentaram nas diferentes partes das plantas, os seguintes teores médios para as determinações bromatológicas, visto que os genótipos avaliados não diferiram quanto a esses teores:

Partes da Planta
Folhas $\quad$ Vagens Talos Finos

\begin{tabular}{lrrr}
\hline PB & 18,57 & 21,68 & 6,41 \\
FDN & 29,09 & 41,58 & 71,01 \\
P & 0,12 & 0,22 & 0,06 \\
Ca & 1,39 & 0,36 & 0,49 \\
Mg & 0,51 & 0,28 & 0,24 \\
Tanino & 1,32 & 1,15 & 0,28 \\
DV & 58,39 & 61,22 & 33,61 \\
\hline
\end{tabular}

\section{REFERÊNCIAS BIBLIOGRÁFICAS}

ASSOCIATION OF OFFICIAL AGRICULTURAL CHEMISTS. Official methods of analysis. 12.ed. Washington: $1970.1094 p$.

BURNS, R.E. Methods of tannin analysis for forage crop evaluation. Athens, Georgia, Agricultural Experiment Stations, 1983. (Technical Bulletin, 32).

GARCIA, R. Banco de proteína. In: CONGRESSO BRASILEIRO DE PASTAGENS e SMMÓSIO SOBRE MANEJO DE PASTAGENS, 8.,Piracicaba, 1986. Anais. Piracicaba, FEALQ, 1986.

HUTTON, E.M. Interelaction of $\mathrm{Ca}$ and $\mathrm{Al}$ in adaptation of Leucaena to very acid soils. Lencaena Research Reports, Taipei-Tailândia, v.3., p.9-11, 1982.
JONES, R.J. El valor de Leucaena leucocephala como pienso para ruminantes en los tropicos. Revista Mundial de Zootecnia ( $n^{\circ}$ 21). FAO Roma, 1979 apud GARCIA, $R$. Banco de proteína no In: CONGRESSO BRASILEIRO DE PASTAGENS e SIMPÓSIO SOBRE MANEJO DE PASTAGENS, 8., Piracicaba, 1986. Anais. Piracicaba: FEALQ, 1986.

KLUTHCOUSKI, J. Leucena: alternativa para a pequena e média agricultura, 2.ed. Goiânia, EMBRAPACNPAF, 1982. 12p. (EMBRAPA-CNPAF. Circular Técnica, 6).

PARBERY, D.P. Pasture and fodder crop plant production at Kimberley Research Station, W.A. 1963-64. Part I. Perennial legumes. CSIRO, Aust. Divn Land Res., (Tech. Mem. 67/6.) 1967. Apud SKERMAN, P.J. Tropical Forage Legumes. In: FAO. Plant Production and Protection. Roma, FAO, 1977. p.511-519. (FAO. Série, 2).

SARRUGE, J.R.; HAAG, H.P. Análises químicas em plantas. Piracicaba, ESALQ/USP, 1974. 56p.

SEIFFERT, N.F.; THIAGO, K.R.L. Legumineira: cultura forrageira para produção de proteína. Campo Grande, EMBRAPA-CNPGC, 1983. 52p. (EMBRAPA, CNPGC. Circular Técnica, 13).

SILVA, D.J. Análise de alimentos (métodos químicos e biológicos). Viçosa, Imprensa Universitária da UFV, 1981. 166p.

SOEST, P.J., van. Use of detergents in the analysis of fibrous feeds. II. A rapid method for the determination of fiber and lignin. Joumal of the Association Official Agronomy Chemical, v.46, n.5, p.824-835, 1963.

UPADHYAY, V.S.; REKIB, A.; PATHAK, P.S. Nutritive value of Leucaena leucocephala (Lam.) de Wit. Indian Veterinary Journal, v.51, p.534-537, 1974.

Enviado para publicação em 25.01 .93

Aceito para publicação em 20.09 .93 